\title{
Technique Reducing Power Loss in Three-Level DC-DC Converter Devices with Zero-Voltage and zero-Current Switching Method
}

\author{
Arckarakit Chaithanakulwat \\ Dhonburi Rajabhat University Samut Prakan campus, 59/1 Village no. 14, Soi Poo Municipality 119, Sukhumvit Road, Bangplli \\ District, Samut Prakan 10540
}

Received 11 February 2020; Accepted 10 July 2020

\begin{abstract}
This research paper presents zero-voltage and zero-current switching method for full-wave three-level DC-DC converters, to reduce power loss due to switching of devices in the DC-DC converter. Principles and methods of reducing power loss for this research will be used to switch devices when turn-on and turn-off by controlling the generation of PWM signals with phase shifting with microcontroller DSPTMS320F28377S. The results, when simulated by MATLAB/Simulink program, compare with the prototype, found that when combined with the non-linear load in the ZVZCS state, the efficiency is equal to $89.90 \%$. Accordingly, connected to the non-linear load in the noZVZCS state, the efficiency is equal to $81.20 \%$.
\end{abstract}

Keywords: Zero-Voltage Switching, Zero-Current Switching, DC-DC converter, Phase Shifting, Reduce Power Loss

\section{Introduction}

DC-DC converters used with switching power supplies often experience power loss from device switching. Works requiring high-power and high-frequency power often result in increased power loss from device switches, and the efficiency of the DC-DC converter is also reduced. The problem is therefore extensively investigated by researchers and found that the use of gentle switch principles can reduce energy loss. This principle has various conditions and methods such as zero-voltage switching (ZVS), zero-current switching (ZCS), accordingly the switch is at zero-voltage zero-current switching (ZVZCS) etc. Reducing the power loss due to the switch means that the voltage and current waveforms of the switch do not overlap, which will cause no loss. This type of zero-voltage switching occurs during the turn-on of the device. Moreover, zero-current switching occurs during turn off. Both techniques also lose power at the beginning of the current and stop conducting the same.

A zero-voltage and zero-current-switching (ZVZCS) PWM combined three-level DC-DC converter, the advantage is that all switch devices operate at only half the voltage. Moreover, the filtered voltage will get the output close to the output voltage, allowing the inductor to be filtered very and also resulting in the voltage of the rectifier decreasing as well [1]. Soft switches pulse width modulation of the DC-DC fullbridge converter with the control of the secondary rectifiers of high-frequency transformers. Nevertheless, the switching device will use the control snubber circuit on the secondary side of the high frequency transformer for creating the control algorithm PWM for use in the opening and closing conditions of zero-voltage and zero-current. Consequently, using a snubber circuit can recover energy as the voltage transistor can be turned off at the center on the secondary side of the

*E-mail address: chaithanakul@gmail.com

ISSN: 1791-2377 @ 2020 School of Science, IHU. All rights reserved.

doi:10.25103/iestr.134.12 transformer [2]. Modulation format for converters dualactive-bridge (DAD) to reduce rms current in a variety of operating conditions. Nevertheless, use the basic fundamental duty modulation (FDM) principles for component analysis, the dual-active-bridge, by modifying the PWM signal in the best FDM basic domain to be used with simple controllers without classifying the calculation mode. The operating characteristics, including the size, rms currents and characteristics of ZVS, will be analyzed to compare the loss of the principles presented with the latest related work. The proposed FDM confirms the operation of high efficiency modulation under wide operating conditions due to reduced heat [3]. A novel zero-voltage and zero-current switching (ZVZCS) pulse width modulation half-bridge three-level DCDC converter, compared with traditional ZVZCS PWM threelevel DC-DC converter. Nevertheless, this converter does not include an additional resonant circuit, it can be used with switching ZVS devices consisting of inductors, capacitors and snubber. This converter can effectively reduce the voltage and the spikes of the switch device and effectively reduce the loss of current. The working principle of the new converters and soft-switch deployment conditions is analyzed according to the equivalent circuits in each step, able to confirm satisfactory operation [4]. A new converter using DT-ADB asymmetric double transformers with secondary phase change control strategies. The main side of the DT-ADB converter will be a full bridge and the second side is a semiautomatic bridge consisting of one active leg and two passive legs. The current and power of the transformers is automatically shared using the primary-side-series and secondary-side-parallel configuration and the ratio of the two transformers. The high-frequency link inductors are reduced as the voltage applied to the inductors decreases compared to the converters, resulting in better efficiency and energy. Zero voltage activation of all active switches and zero-current turnoff of all diodes can be achieved over a wide operating range, resulting in the loss of on-off of the secondary switch used. The work is reduced because half of the output current 
flowing through the switch. The proposed topology also has the advantages of continuous output currents and small output filter requirements, resulting in good performance [5]. High efficiency and high power density can be achieved with DCDC transformers by operating all switch devices at a $50 \%$ duty cycle, but the output voltage of DC-DC transformers cannot be controlled. The output voltage of this uncontrollable DC-DC transformer uses a rectifier ABRS, fundamentally $\mathrm{ABR}$ consists of a traditional rectifier diode and a bidirectional switch. Where ABR is used for controlling the phase change between primary and secondary switch that can adjust the output voltage. For this reason, the softswitching DC-DC converter will be used in the continuous conductivity mode, resulting in improved ZVS performance. In addition, the diode recovery problems were alleviated using the ABR control scheme [6]. The development of a soft switch for a five level dc-dc converter is used for zero voltage switching conditions for all control switch devices. This switch device uses pulses from the gate to create a PWM controller. The primary operating mode of the converter offers simulation results and compares the switching loss of the proposed converter with no zero voltage switching model [7]. The strict control of the switching behavior of the switch in the process of turning on and off the power device must withstand high voltage currents resulting in high stress and high switching loss. The switching loss is directly proportional to the switching frequency. The device can help to reduce the maximum switch frequency with an electrical power converter. Therefore, using ZCS, or ZVS will allow the switch to control power. In general, resonance occurs during the closing and opening processes in the ZCS and ZVS generation process. The offering of multiple DC-DC converters with three and five controllers under ZVS conditions consists of three outputs and two asymmetric converters, which are controlled depending on the phase change between the two asymmetrical converters [8]. This research therefore developed a technique of zero-voltage zero-current switching (ZVACS) to combine the advantages and disadvantages of both methods. This reduces the power loss in both the turn-on phase and the turn-off period as intended.

\section{Proposed Scheme and Related Principles}

Zero-current and zero-current switch efficiency analysis for full-wave three-level DC-DC converters, in order to reduce power loss due to switching of devices in the dc-dc converter [9]-[13]. This research, use of PWM phase shift controls accordingly reverse control to control the power supplied to the non-linear loads. The mechanism of this prototype consists of two parts: the first part is a three-level DC-DC converter using ZVZCS switching technique, the second part is to control the three-level DC-DC converter with techniques for switching ZVZCS.
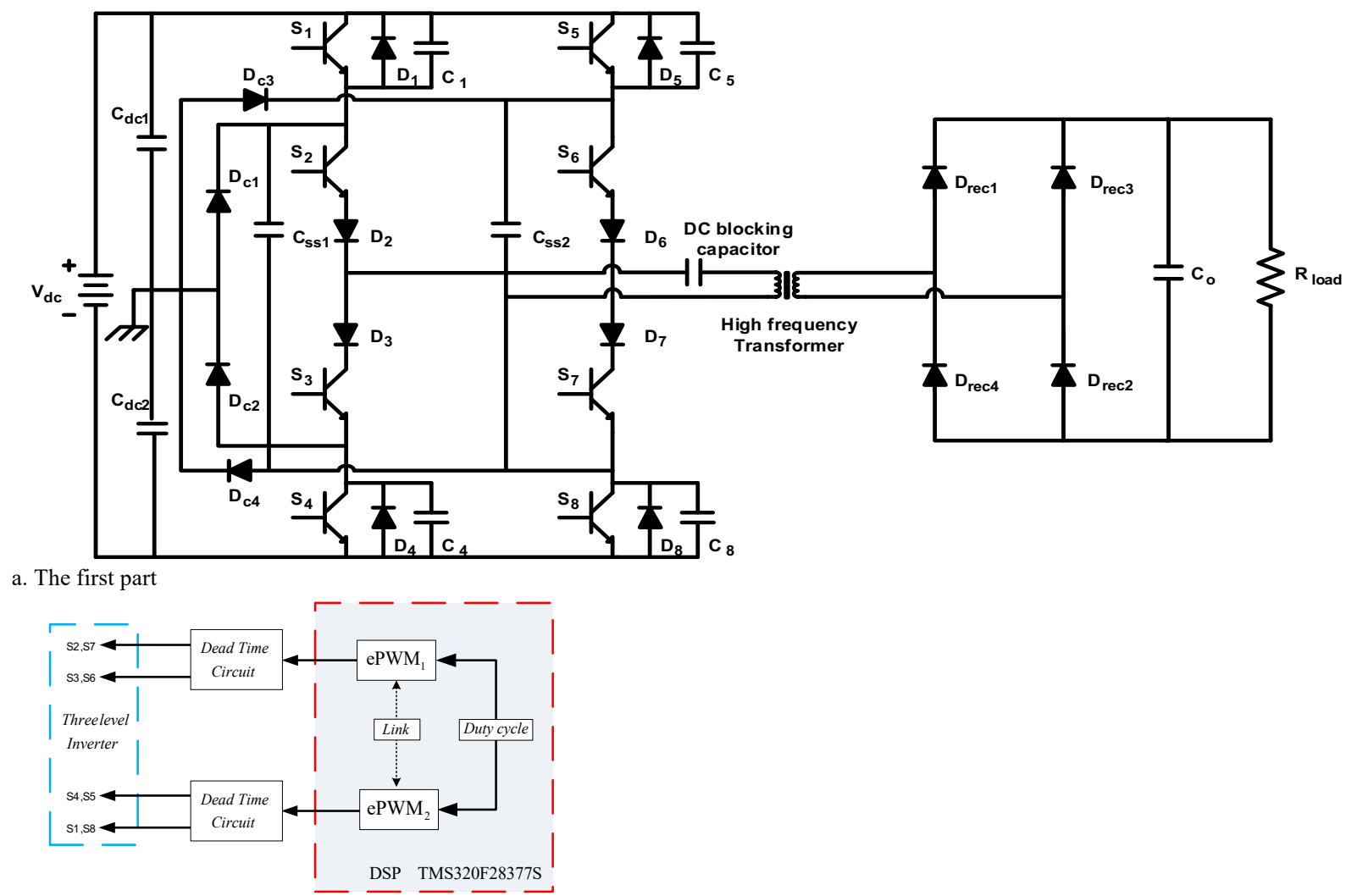

b. The second part

Fig. 1. Diagram mechanism of this prototype

Fig. 1, the DC-DC three-level converter is a used for supplying non-linear loads, with the three-level DC-DC converter converting DC voltage from available sources constantly to get the output to DC voltage. Nevertheless, when the load changes, the output power of the three-level dcdc converter circuit will change accordingly. This research is to reverse control to control the output power to be stable. the power component of the three-level DC-DC converter consists of a three-level full bridge circuit, blocking capacitors, high-frequency transformers, rectifiers, filter capacitors (Fig.1a.) and control of the DC-DC converter with three levels (Fig. 1b.).

\subsection{The Three Level Full Bridge Principles}


Considering Fig 2a. is a three-level full-bridge circuit diagram, typical three-level full bridge circuits consisting of two branches of three-level full bridge circuits: branches of phase A accordingly branches of phase $\mathrm{B}$, each the branches consist of four switches, with external switches namely $S_{1}, S_{4}$, $\mathrm{S}_{5}$ and $\mathrm{S}_{8}$. Nevertheless, this research, the prototype mechanism will use IGBT as a switching device, considering the operation of the diode and the hidden capacitor inside the IGBT. The inner switches, $\mathrm{S}_{2}, \mathrm{~S}_{3}, \mathrm{~S}_{6}$ and $\mathrm{S}_{7}$, will also use IGBT as a switch device, using a series diode with IGBT to enable IGBT to withstand back flow. Fig. $2 b$. is the mechanism of the prototype that was created to test the operation according to the specified objectives.

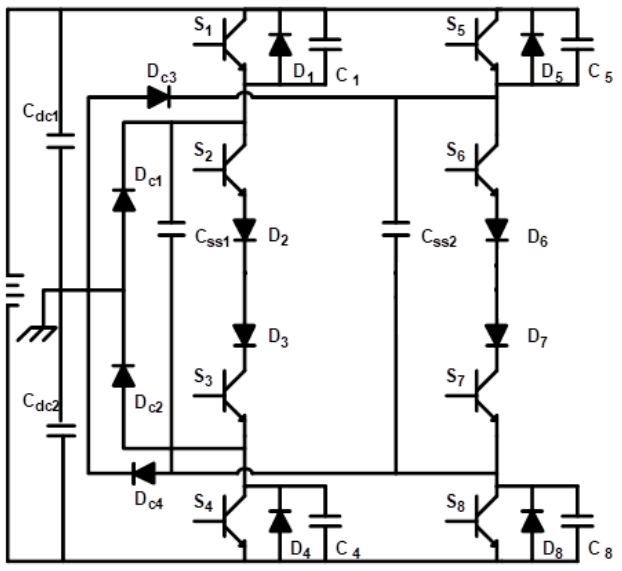

a.

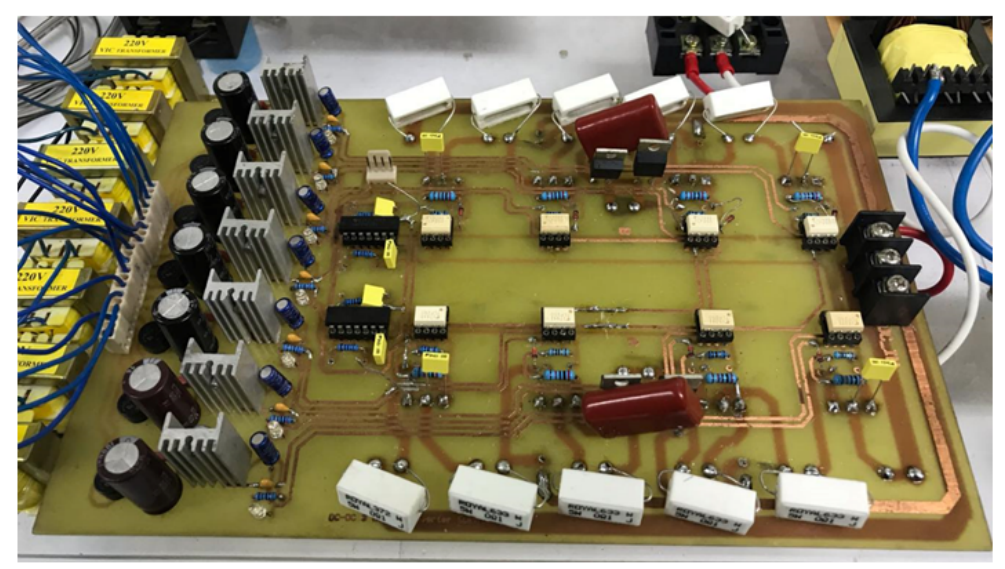

b.

Fig. 2. Three-level full-bridge circuit diagram and prototype

\subsection{The principle of the blocking capacitor}

The capacitors for the blocking are provided for the inner loop switch to stop the current in the zero current state. This reset period $\left(T_{\text {reset }}\right)$ must be less than the phase shift $\left(T_{\text {Shift }}\right)$, because the current must be reduced to zero before the voltage occurs.

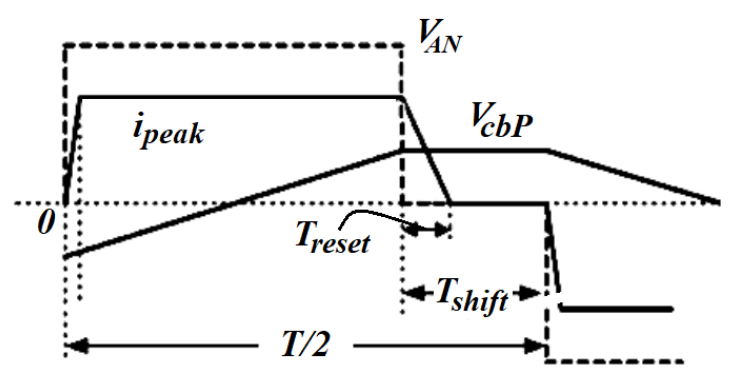

Fig. 3. The waveform characteristics of zvs

Consider Fig 3. If the current is reduced to zero, then it is possible to use a voltage across the capacitor to block. Nevertheless, if the voltage across the capacitor for the blocking is high, the current will drop quickly, in which the voltage drop across the capacitor blocks is

$$
V_{c b P}=\left(\frac{i_{\text {peak }}}{2 \times C_{b c}}\right) \times\left(\frac{T}{2}-T_{\text {shift }}\right)
$$

From the equation (2)

$$
T_{\text {reset }}=\frac{4 \times L_{l k} \times i_{p e a k}}{V_{d c}+4 \times V_{c b P}}
$$

When equating equation (1) instead into the equation (2), will get

$$
T_{\text {reset }}=\frac{4 \times L_{l k} \times i_{\text {peak }}}{V_{d c}+4 \times\left[\left(\frac{i_{\text {peak }}}{2 \times C_{b c}}\right) \times\left(\frac{T}{2}-T_{\text {shift }}\right)\right]}
$$

Consequently, the capacitance of the blocking can be found from equation (4)

$$
C_{b c}=\frac{i_{\text {peak }} \times\left(\frac{T}{2}-T_{\text {shift }}\right)}{\left(\frac{2 \times L_{l k} \times i_{\text {peak }}}{T_{\text {reset }}}-\frac{V_{d c}}{2}\right)}
$$

The advantage of using a blocking capacitor to reduce the current to zero is that it is convenient to find a capacitor. Moreover, there is a disadvantage that causes the voltage across it, causing loss of power before distribution to the transformer. Consequently, reducing the input power of the transformer.

\subsection{Switch Control of ZVZCS}

The ZVZCS switching control uses phase-shift PWM signals to control the conductivity and stop the IGBT current. This principle is used for driving the inner switch device of the DCDC converter as shown in Fig 4. Nevertheless, considering from Fig. 4, it was found that programming for controlling the microcontroller DSPTMS320F28377S, the researchers used MATLAB/Simulink program for writing the algorithm for computer processing.

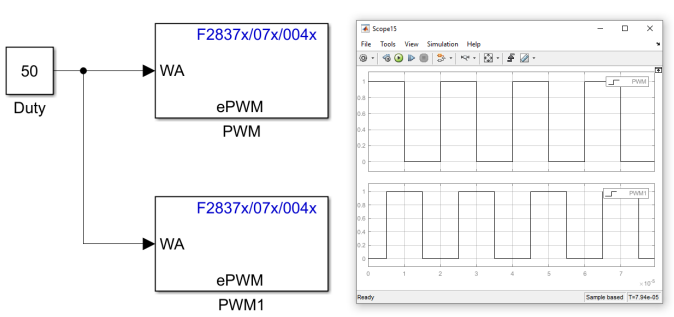

Fig. 4. Microcontroller DSPTMS320F28377S phase-shift control 


\section{Results and Analysis}

This topic is the result of a three-level DC-DC converter test using zero-current and zero-current switching techniques for linear and non-linear loads. This research will simulates theoretical features with the MATLAB/Simulink program compared to the prototype device created. The test will consist of phase shift PWM signal control with microcontroller DSPTMS320F28377S, zero-voltage and zero-current switching devices, the study of the behavior of the blocking capacitors and comparison of zero-voltage and zero-current switching and no-zero-voltage and zero-current switching. Fig. 5, shows the prototype used to test the operation of the three-level DC-DC converter using the zerovoltage and zero-current switching techniques.

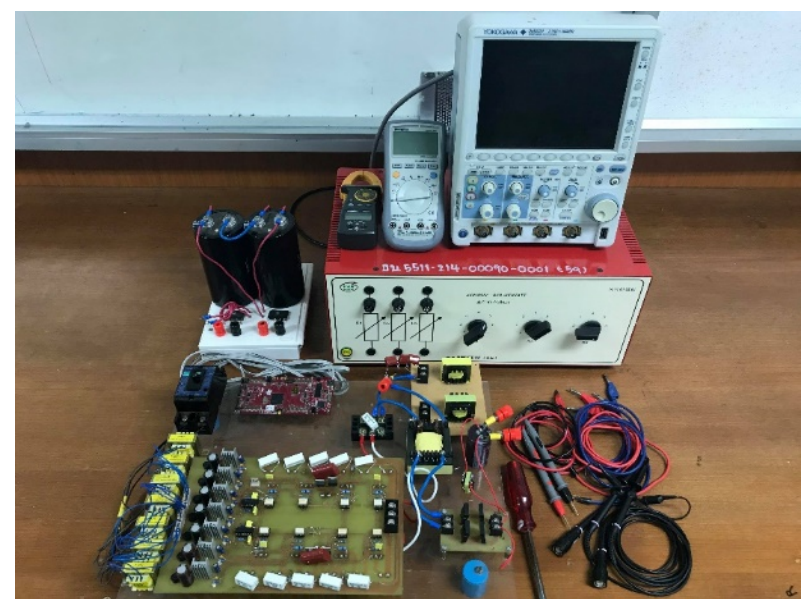

Fig. 5. Prototype of the test

\subsection{The Phase Shift PWM Signal Control}

Phase shifted PWM signal control can be performed using the ePWM block on the program MATLAB/Simulink. The simulation results compared with the prototype device are shown in figure 6 . Will find that the switches $S_{1}$ and $S_{2}$ operate in the same state, so using PWM signals to drive $S_{1}$ switches in the same way as $S_{2}$ and $S_{7}, S_{3}$ and $S_{6}, S_{4}$ and $S_{5}$, then use the PWM signal to switch $S_{2}, S_{3}, S_{4}$ respectively.

\subsection{The Zero-Voltage and Zero-Current Switching \\ Devices}

Testing of all switch devices at power rating, input voltage $311 \mathrm{~V}$, output volts $31 \mathrm{~V}$, accordingly switch frequency 50 $\mathrm{kHz}$. This test is to observe the behavior of the switch device which the test results are shown in Fig 7. From Fig 7a., showing simulation using MATLAB/Simulink program and Fig $7 b$., showing the operation of the $S_{1}$ and $S_{8}$ switches of the prototype device in the current initial state and no initial state, it is found that in the initial state, the voltage across the switch decreases to zero, this state is called zero-voltage switching (ZVS).

Fig. 8a., and 8b., showing the switching status of devices $\mathrm{S}_{2}$ and $\mathrm{S}_{7}$ the current initial state and no initial state, will find that in the current initial state, the voltage drop across the switch device will decrease to zero, so the switch device will stay in the current initial state, this state is called zero-voltage switching (ZVS). Moreover, when the current is reduced to zero so there is a voltage across the switch device, this state is called ZCS. Consequently, from Fig. 9a., and 9b., the switching status of devices $\mathrm{S}_{3}$ and $\mathrm{S}_{6}$ will work in accordance with the above. Fig 10a., and 10b., the operating status of device switches $\mathrm{S}_{4}$ and $\mathrm{S}_{5}$ will correspond to device switches $\mathrm{S}_{1}$ and $\mathrm{S}_{8}$.

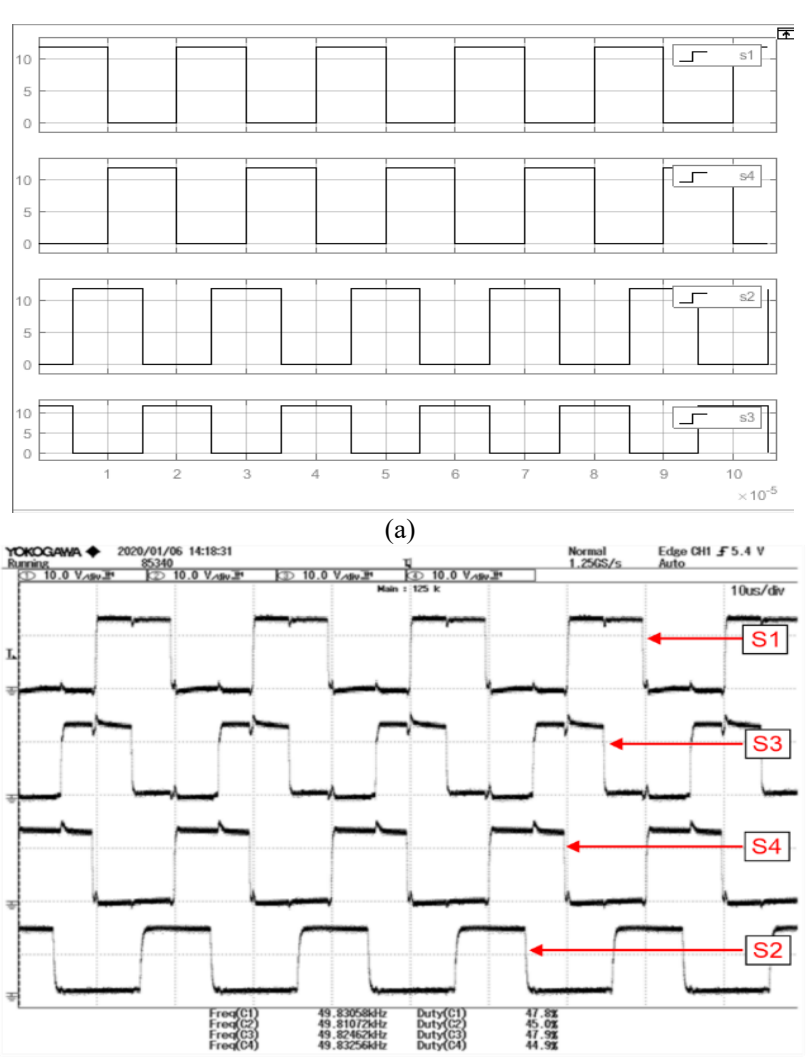

(b)

Fig. 6. Phase Shift PWM Signal Control using the ePWM block, a. simulation result of MATLAB/Simulink and $b$. The result prototype device

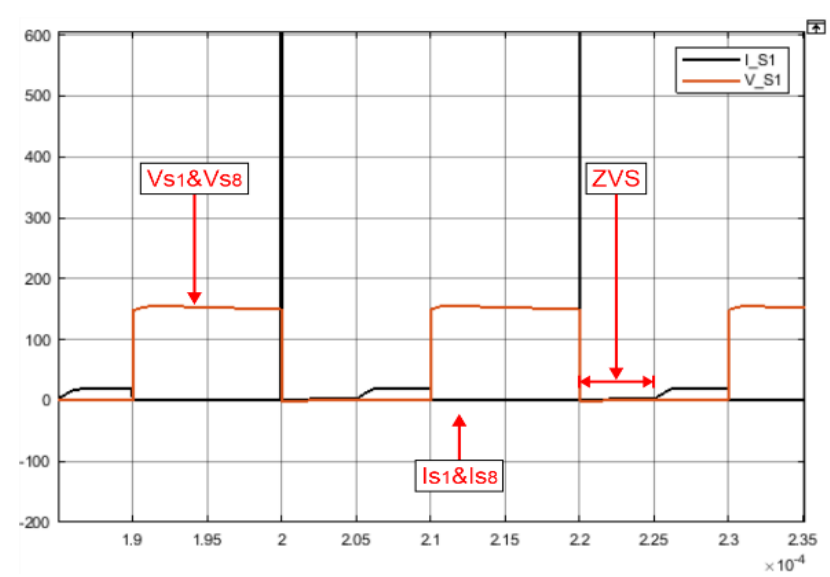

a)
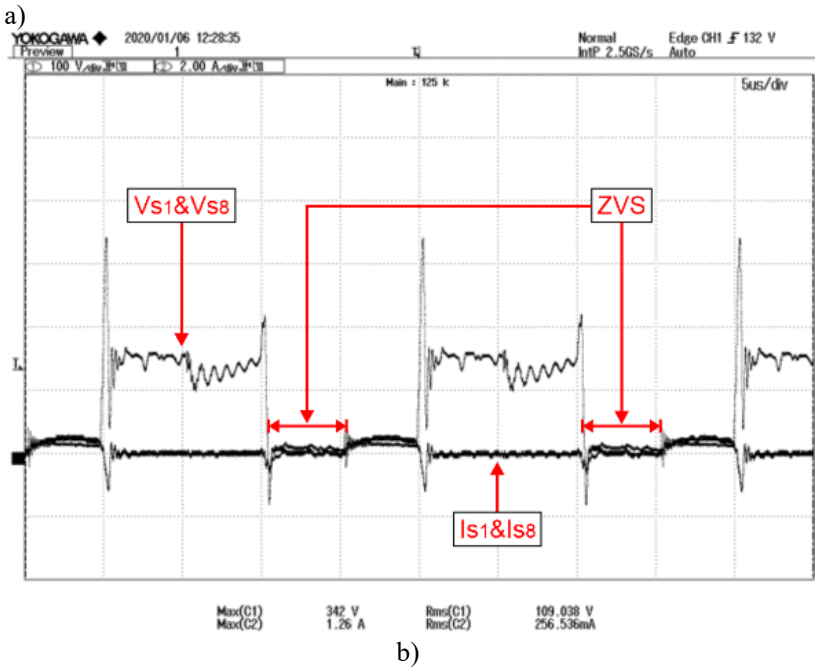

Fig. 7. The operation of the $S_{1}$ and $S_{8}$ switches a)MATLAB/Simulink and $b)$ prototype device 


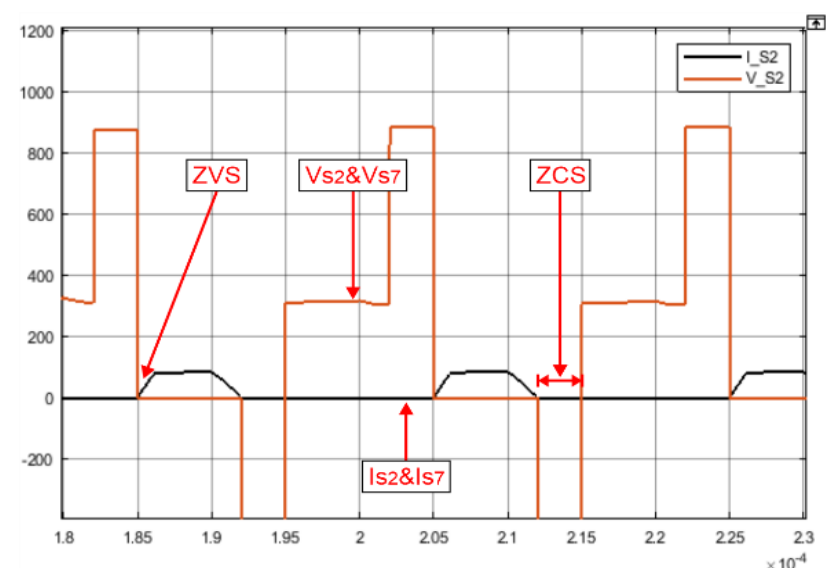

a)

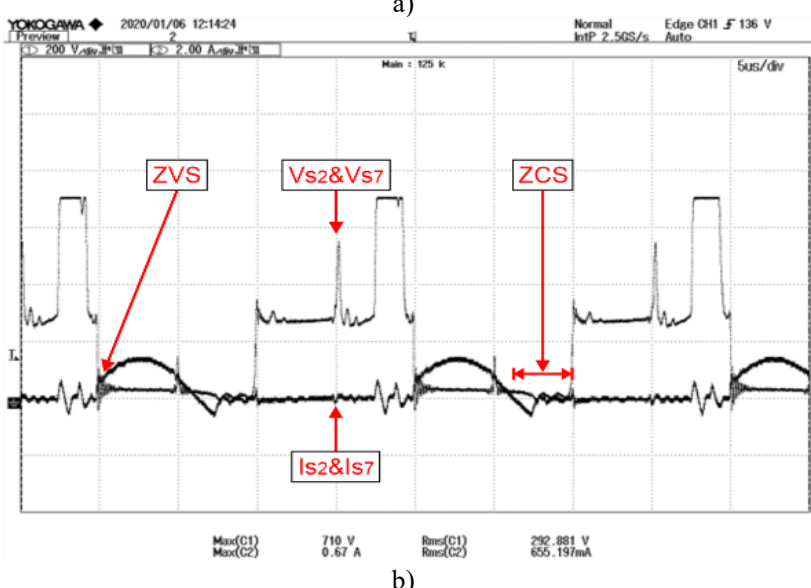

Fig. 8. The operation of the $S_{2}$ and $S_{7}$ switches a)MATLAB/Simulink and b) prototype device
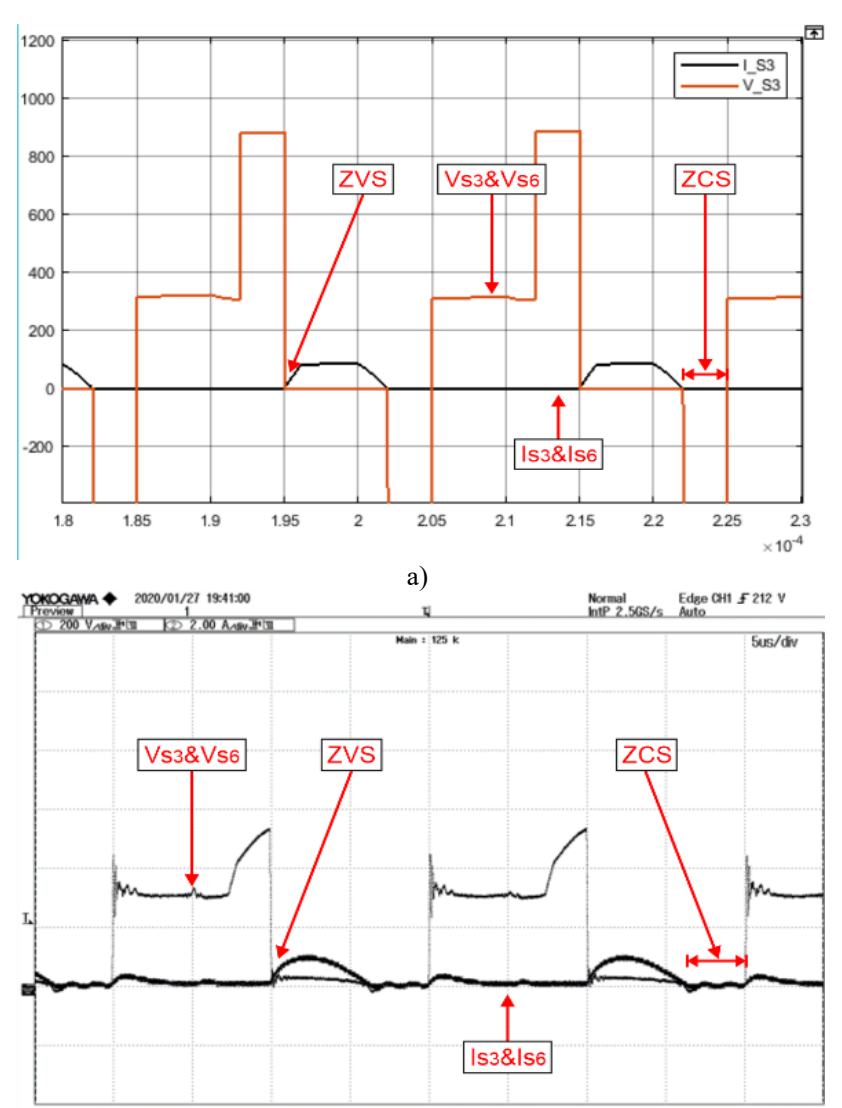

$\operatorname{Max}(\mathcal{M})$

5.16

b)

Fig. 9. The operation of the $S_{3}$ and $S_{6}$ switches a)MATLAB/Simulink and $b$ ) prototype device

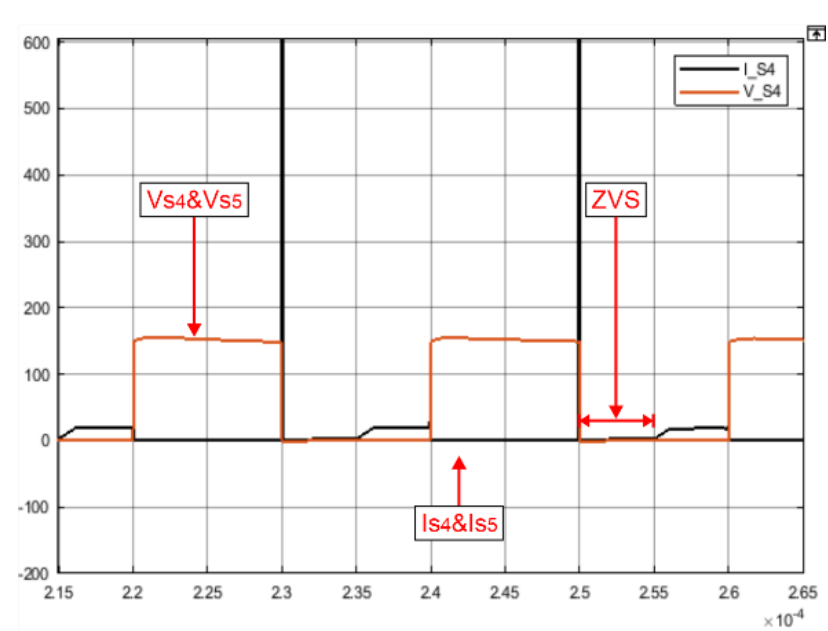

a)

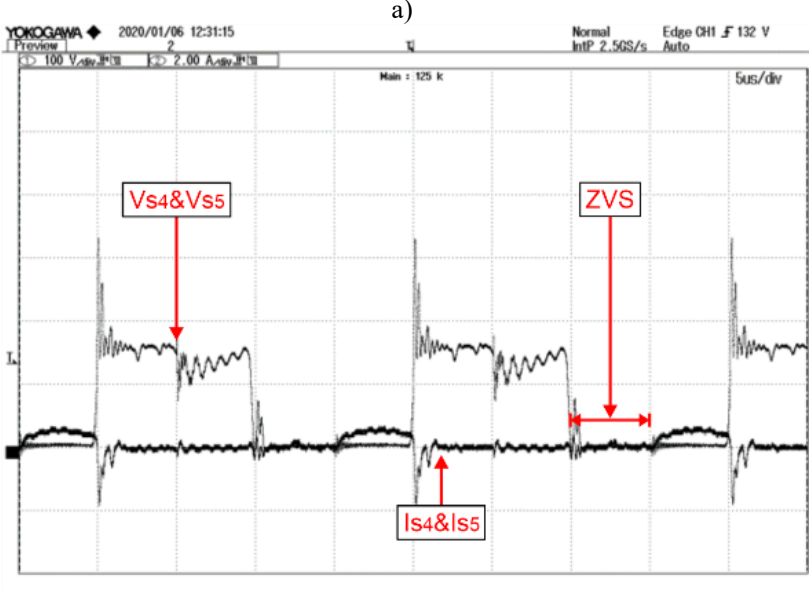

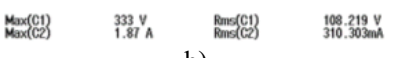

b)

Fig 10. The operation of the $\mathrm{S}_{4}$ and $\mathrm{S}_{5}$ switches a)MATLAB/Simulink and b) prototype device

\subsection{The Blocking Capacitors}

A study of behavior of blocking capacitors affecting the reset time. Will measure the reset time of the primary current compared with the voltage $\left(\mathrm{V}_{\mathrm{AB}}\right)$, when the change of the capacitor blocks from $20 \mu \mathrm{F}$ to $50 \mu \mathrm{F}$. This behavioral study will be simulated using MATLAB/Simulink program in comparison with the prototype device which can be shown in Fig 11 and Fig 12.

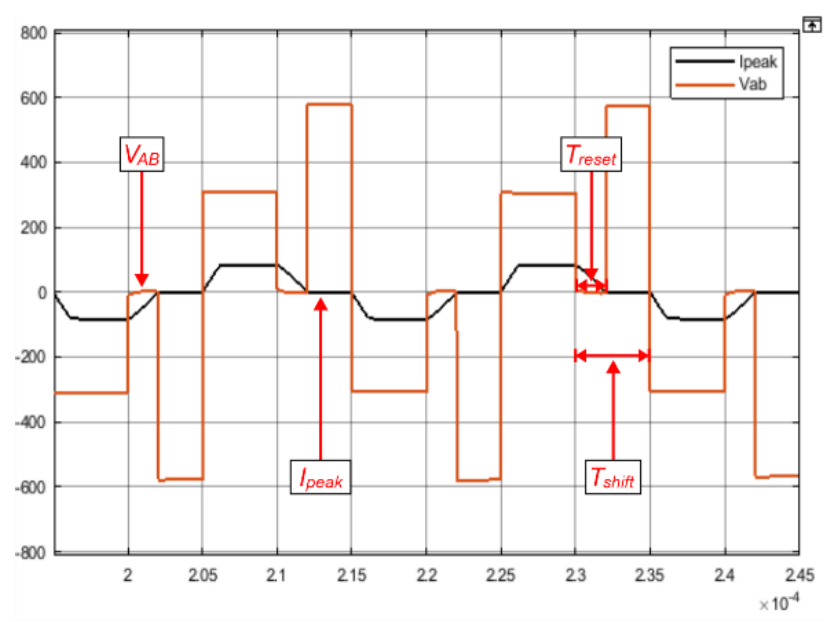

a) 


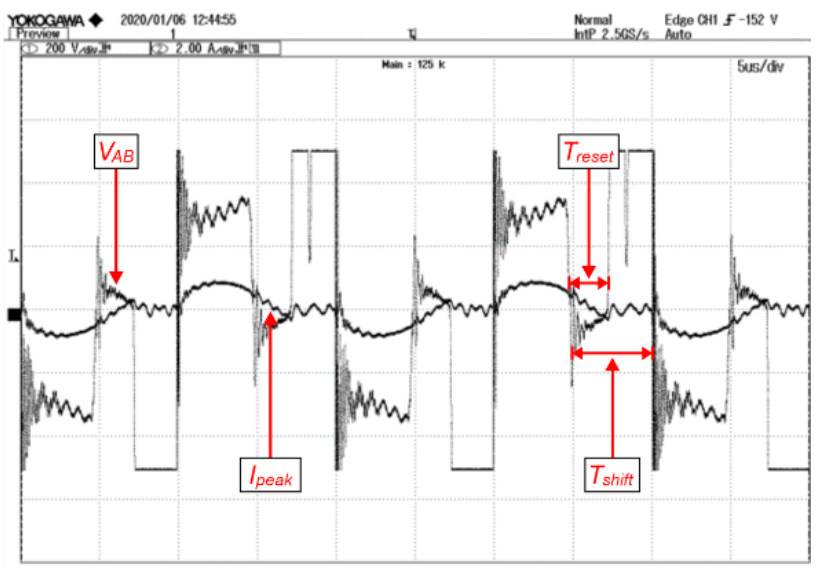

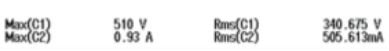

b)

Fig. 11. Signal capacitor blocks from $20 \mu \mathrm{F}$ a)MATLAB/Simulink and b) prototype device

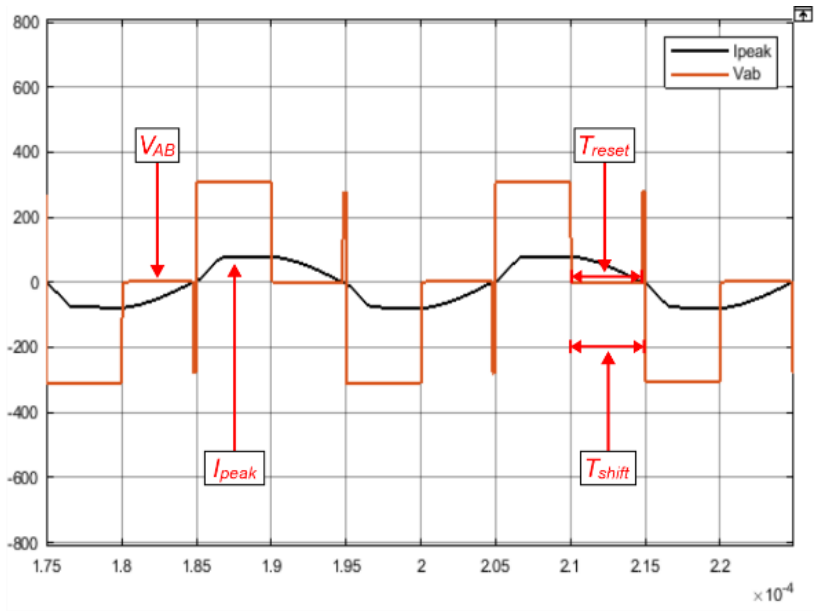

a)

Table 1. Comparison of ZVZCS and non ZVZCS

\begin{tabular}{c|c|c|c|c|c|c|c}
\hline Switching state & $V_{\text {in }}(V)$ & $I_{\text {in }}(A)$ & $P_{\text {in }}(W)$ & $V_{\text {out }}(V)$ & $I_{\text {out }}(A)$ & $P_{\text {out }}(W)$ & Efficiency $(\%)$ \\
\hline ZVZCS & 311.50 & 1.70 & 529.55 & 27.92 & 16.28 & 470.77 & 89.90 \\
NO-ZVZCS & 315.10 & 1.82 & 573.50 & 26.40 & 17.63 & 465.67 & 81.20 \\
\hline
\end{tabular}

Considering the turn-on and turn-off in the switch state when the zero voltage and zero current with the condition of no switch, while the zero voltage and zero current, the behavior will be different as shown in the Fig. 13 to Fig 16.

Fig 13a. and 13b., when testing the switch on $\mathrm{S}_{1}$ and $\mathrm{S}_{8}$ switches with No-ZVZCS, the turn-on range does not turn-on when the device is at zero voltage and the ZVZCS switch test occurs switch while the zero voltage during the turn - on period.

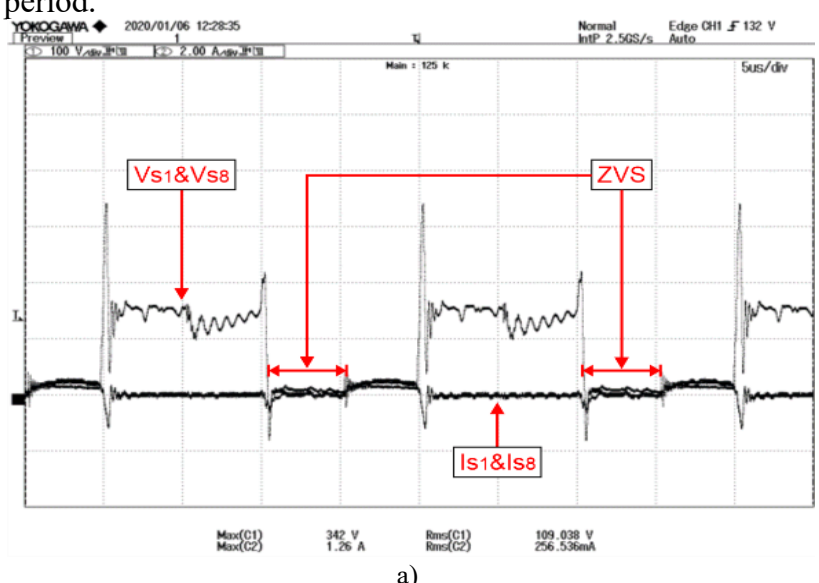

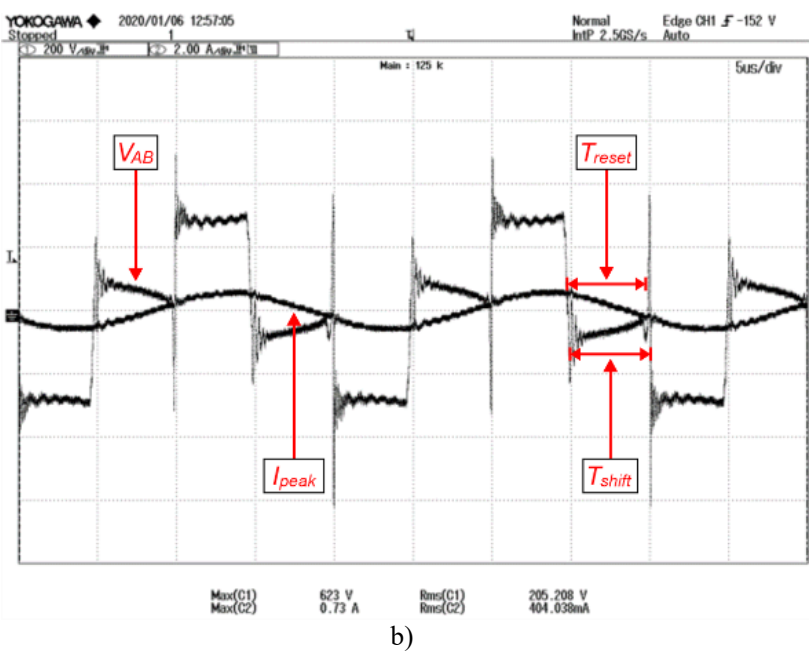

Fig. 12. Signal capacitor blocks from $50 \mu \mathrm{F}$ a)MATLAB/Simulink and b) prototype device

Fig. 11a. and $11 \mathrm{~b}$. It is found that the primary current decreases to zero in the phase shift of PWM signal, this state is called $T_{\text {shift }}$. Moreover, this state of primary current decreasing to zero is called $T_{\text {reset }}$. Nevertheless, it is also found that the $T_{\text {reset }}$ has a time comparable to the $T_{\text {shift }}$, as a result the period of primary current is relatively low, around $0.2 \mu \mathrm{s}$. Fig. $12 \mathrm{a}$. and $12 \mathrm{~b}$., when the capacitor values are changed from $20 \mu \mathrm{F}$ to $50 \mu \mathrm{F}$ the primary current is zero at approximately $2.8 \mu \mathrm{s}$.

\subsection{Comparison of ZVZCS and No- ZVZCS}

Comparison of switching at zero voltage and zero current with no switching zeroes voltage and zero current, will consider both states while connecting non-linear loads at the rating. The test results will be given in table 1 .

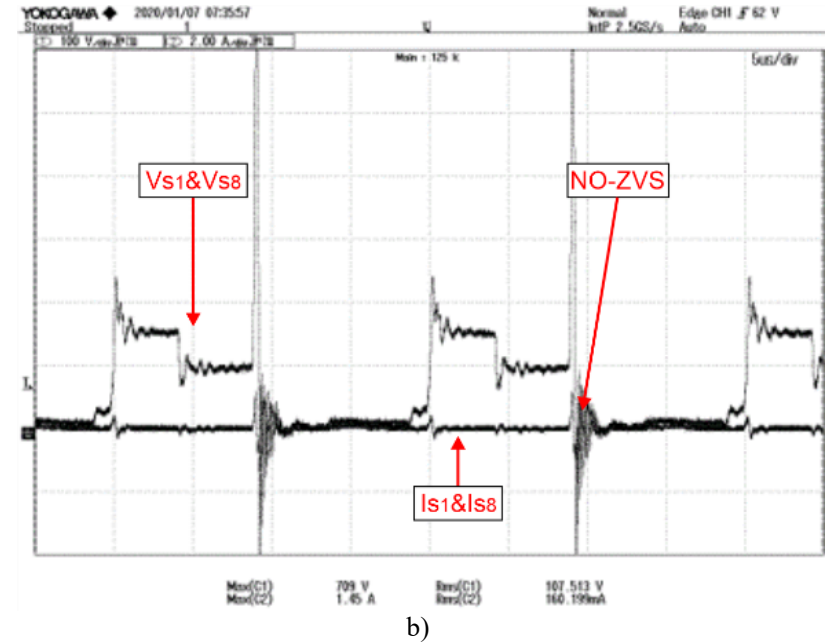

Fig. 13. The operation of the $S_{1}$ and $S_{8}$ switches a) ZVZCS and b) No ZVZCS 

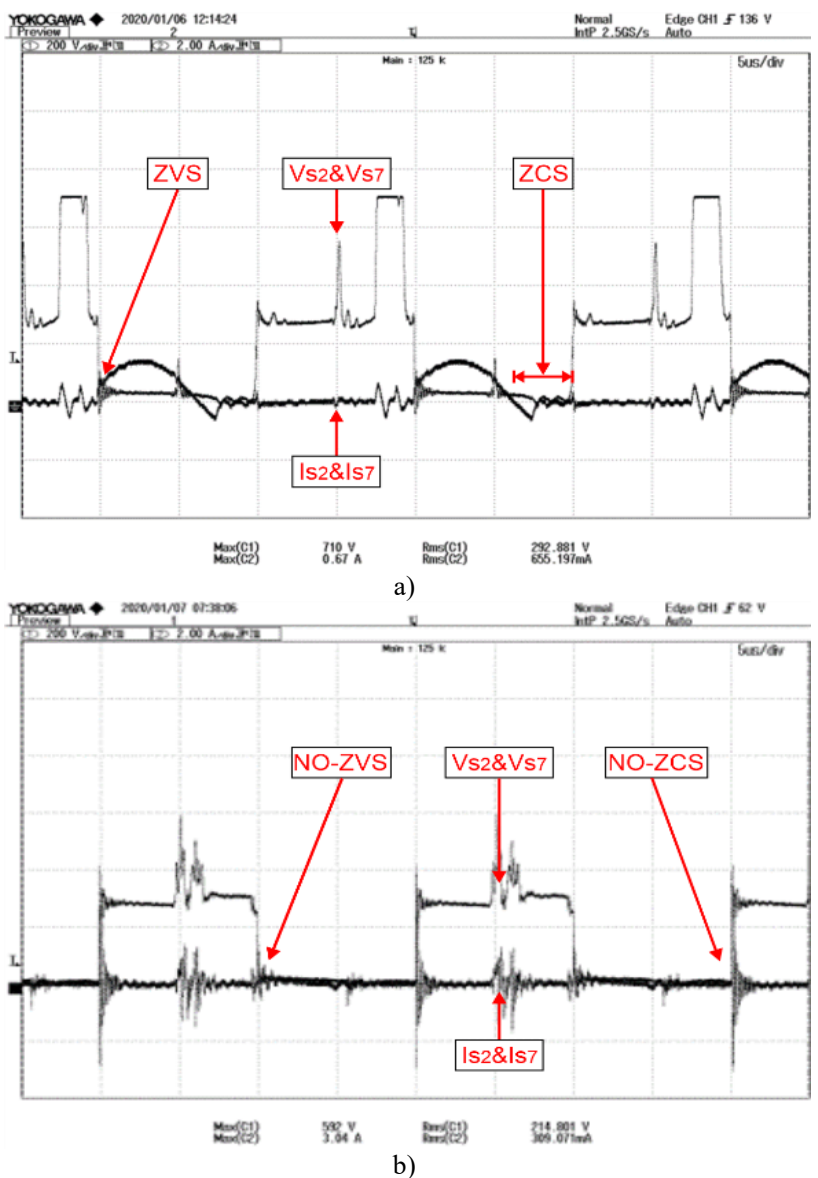

Fig.14. The operation of the $S_{2}$ and $S_{7}$ switches a) ZVZCS and b) No ZVZCS
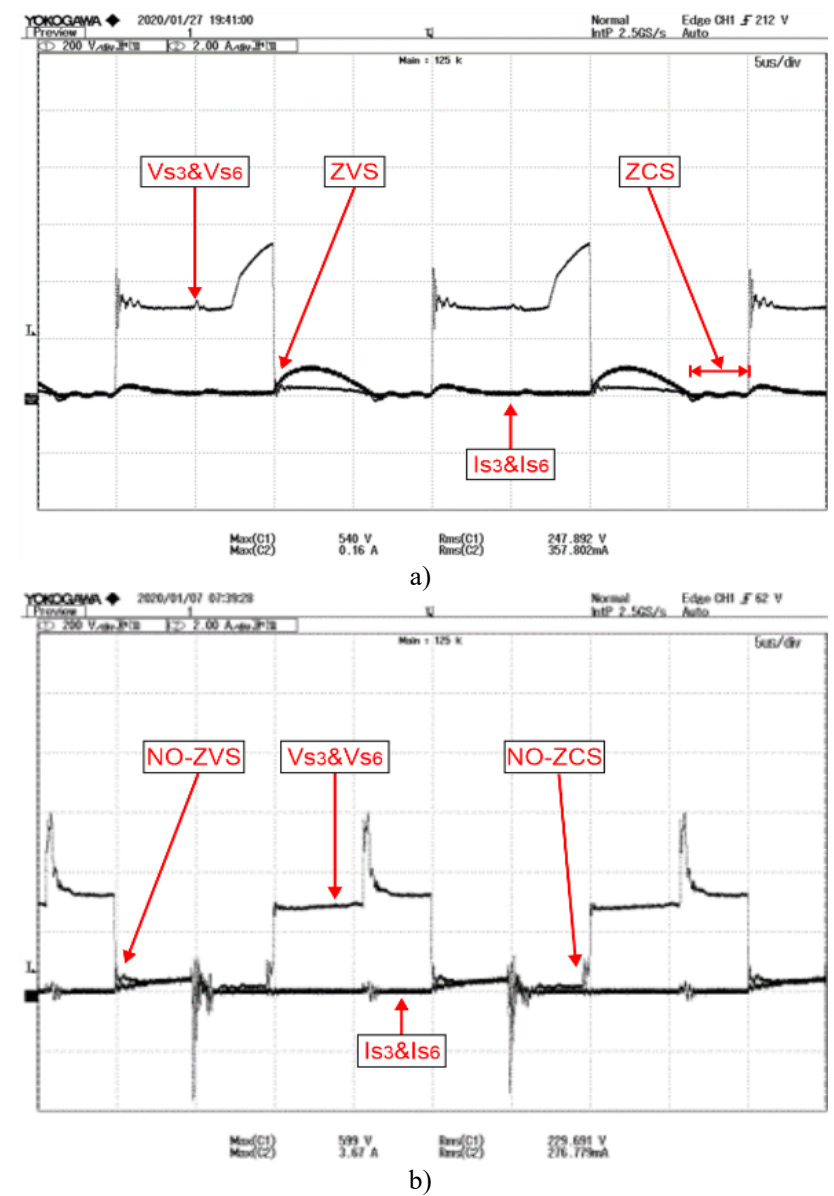

Fig. 15. The operation of the $S_{3}$ and $S_{6}$ switches a) ZVZCS and b) no ZVZCS
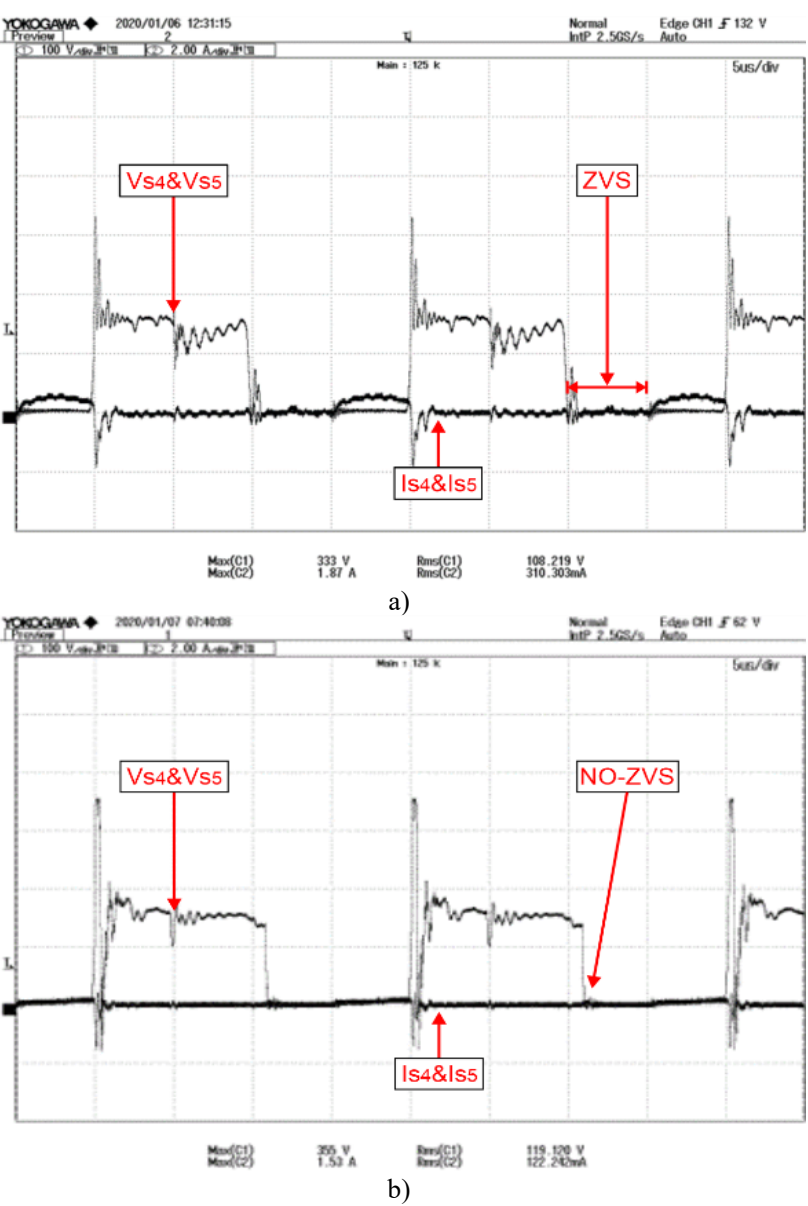

Fig. 16. The operation of the $S_{4}$ and $S_{5}$ switches a) ZVZCS and b) no ZVZCS

Fig. 14a., 14b. And Fig. 15a., 15b., when testing the switching of $\mathrm{S}_{3}$ and $\mathrm{S}_{6}$ No-ZVZCS and ZVZCS. The behavior is in the opposite state to $S_{2}$ and $S_{7}$ because the PWM signal that causes the switch devices of $\mathrm{S}_{3}$ and $\mathrm{S}_{6}$ to operate, is the correct signal with phase from the signal that causes the $S_{2}$ and $\mathrm{S}_{7}$ switches to operate. Conversely, Fig. 16a. and 16b., the operation of the switches $\mathrm{S}_{4}$ and $\mathrm{S}_{5}$ will operate with the phase signal that is correct from the signal that causes the switch $\mathrm{S}_{1}$ and $\mathrm{S}_{8}$.

\section{Conclusion}

The results of the research on the topic of zero-voltage switching and zero-current for full-wave three-level DC-DC converters to reduce power loss due to device switching. Nevertheless, using the device switch when turn-on and turnoff by controlling the PWM signal that moves through the phase microcontroller DSPTMS320F28377S. The prototype test results compared with the simulation by MATLAB/Simulink program confirm the accuracy as specified. Moreover, can increase the electric power and reduce the loss in the switch equipment, resulting in satisfactory performance.

\section{Acknowledgements}

The work and publications are supported by the Department of Electrical Engineering, Dhonburi Rajabhat University. This article would not have been completed without the support of the entire Mr Add Choedphongsa, a technical assistant. 
This is an Open Access article distributed under the terms of the Creative Commons Attribution License

\section{References}

[1] Fuxin Liu ; Jiajia Yan ; Xinbo Ruan, "Zero-Voltage and ZeroCurrent-Switching PWM Combined Three-Level DC/DC Converter" IEEE Transactions on Industrial Electronics, Vol. 57(5) pp. 1644 - 1654, 2010. https://doi.org/10.1109/TIE.2009.2031950.

[2] Jaroslav Dudrik, Marek Pástor, Milan Lacko, Róbert Žatkovič, "Zero-Voltage and Zero-Current Switching PWM DC-DC Converter Using Controlled Secondary Rectifier With One Active Switch and Nondissipative Turn-Off Snubber", IEEE Transactions on Power Electronics Vol. 33(7), pp. 6012 - 6023, 2018. https://doi.org/ 10.1109/TPEL.2017.2748569.

[3] Wooin Choi, Kyung-Min Rho, Bo-Hyung Cho, "Fundamental Duty Modulation of Dual-Active-Bridge Converter for Wide-Range Operation" IEEE Transactions on Power Electronics Vol. 31(6), pp. 4048 - 4064, 2016. https://doi.org/10.1109/TPEL.2015.2474135

[4] E., Chu, X. Hou, H. Zhang, M. Wu, X. Liu, "Novel zero-voltage and zero-current switching (ZVZCS) PWM three-level DC/DC converter using output coupled inductor", IEEE Transactions on Power Electronics., vol. 29(3), pp. 3501-3513, 2014. https://doi.org/10.1109/TPEL.2013.2260174

[5] H. Wu, L. Chen, Y. Xing, "Secondary-side phase-shift-controlled dual-transformer-based asymmetrical dual-bridge converter with wide voltage gain", IEEE Transactions on Power Electronics., vol. 30(10), pp. 5381-5392, 2015. https://doi.org/10.1109/TPEL.2014.2371922.

[6] H. Wu, Y. Lu, T. Mu, Y. Xing, "A family of soft-switching DC-DC converters based on phase-shift-controlled active boost rectifier", IEEE Transactions on Power Electronics., vol. 30, no. 2, pp. $657-$ 667, 2015. https://doi.org/ 10.1109/TPEL.2014.2308278.

[7] V. Sivaparvathi, SRI. J. Sivavara Prasad, "Five-Level Full-Bridge Zero Voltage and Zero Current Switching DC-DC Converter Topology" International Journal for Innovative Research in Science \& Technology, Vol. 1(11), pp. 1-12, 2015.

[8] Prasad J, Obulesh YP, Babu CS, "Closed Loop Control of Zero Voltage Switching DC-DC Converter to Generate Three Outputs"
Journal of Electrical \& Electronic Systems, Vol. 4 (3), pp. 1-12, 2015. https://doi.org/ 10.4172/2332-0796.1000156.

[9] Chaithanakulwat, A., Kinnares, V. "Implementation of a low-cost single-phase grid-connected photovoltaic system with active power filtering mechanism. International Review of Electrical Engineering $\begin{array}{lllll}\text { (IREE) } & \text { Vol. } & 12 & \text { pp. } & 175-182,\end{array}$ https://doi.org/10.15866/iree.v12i2.11383

[10] Chaithanakulwat, A. "Multi-functionality control, power filtering single-phase grid-connected photovoltaic system. American Journal of Electrical Power and Energy Systems", Vol. 8, No. 2, pp. 62-70, 2019. http://doi.org/10.11648/j.epes.20190802.14

[11] Chaithanakulwat, A. "Track the maximum power of a photovoltaic to control a cascade five-level inverter a single-phase grid-connected with a fuzzy logic control". International Journal of Power Electronics and Drive Systems (IJPEDS), 10(4): 1863-1874, 2019. http://doi.org/10.11591/ijpeds.v10.i4

[12] Chaitanakulwat, A., Kinnares, V., Thungsuk, N. "Single-phase gridconnected photovoltaic system with active power filter functionality". In 2012 15th International Conference on Electrical Machines and Systems (ICEMS). pp. 1-3, 2012.

[13] Chaithanakulwat, A. "Design of solar-powered aeration system for shrimp ponds of farmers in Thailand". European Journal of Electrical Engineering, Vol. 21, No. 6, pp. 539-546, 2019. https://doi.org/10.18280/ejee. 210608

[14] Boontua, S., Chaithanakulwat, A., Savangboon, T., "Power Quality Improvement with Mitigation of Harmonic Distortion in Threephase System Based on Shunt Active Power Filter Mechanism". International Journal on Engineering Applications (IREA), Vol. 7, No.6, pp. 188-196, 2019. https://doi.org/10.15866/irea.v7i6.17180

[15] Chaithanakulwat, A. "Development of DC voltage control from wind turbines using proportions and integrals for Three-phase gridconnected inverters". International Journal of Electrical and Computer Engineering (IJECE), 10(2): 1701-1711, 2020. http://doi.org/10.11591/ijece.v10i2. 